\title{
Measuring financial literacy of university students
}

\author{
Ana Pavković, ${ }^{1, *}$, Mihovil Anđelinović ${ }^{1}$ and Domagoj Mišević ${ }^{2}$ \\ ${ }^{1}$ Faculty of Economics and Business, University of Zagreb \\ J. F. Kennedy Square 6, 10000 Zagreb, Croatia \\ E-mail: 〈\{ana.pavkovic, mandelinovic\}@efzg.hr〉 \\ ${ }^{2}$ Porezno savjetovanje Javorović, Idžojtić i partneri Ltd. \\ Vlaška 94, 10000 Zagreb, Croatia \\ E-mail: 〈domagoj.misevic@porezno-savjetovanje.com.hr〉
}

\begin{abstract}
Defining and properly measuring financial literacy of students is a prerequisite for proposing education policy solutions. The main objective of this paper is to present a procedure of financial literacy assessment. The measure is based on the results of the survey conducted on a suitable sample of students at the University of Zagreb. It is developed using confirmatory factor analysis, which involves testing the validity of a measurement model. This model consists of four manifest variables: Knowledge, Attitudes, Behavior and Practical Knowledge, which are used to estimate a composite measure of financial literacy. The results of factor analysis were later used for obtaining the corresponding weights of indicators of financial literacy. The estimated measure indicates great heterogeneity in the level of financial literacy among students from different constituent units of the University of Zagreb.
\end{abstract}

Keywords: financial literacy, confirmatory factor analysis, students, maximum likelihood estimation, eigenvector method

Received: June 4, 2017; accepted: March 28 2018; available online: July 24; 2018

DOI: $10.17535 /$ crorr.2018.0008

\section{Introduction}

Nowadays, financial products and services are growing more complex, creating new pitfalls for consumers and providing greater potential for financial frauds and mismanagement. Previous studies have shown that the student population, together with the aging population, makes a vulnerable group of citizens when financial literacy is concerned. That is why many of the higher education institutions have introduced formal financial education, and rational education policies require modeling. In such a model, financial literacy is an input to model the need for financial education, and it needs to be validly measured for a correct assessment of educational outcomes. The main aim of this paper is to present a method of measuring students' financial literacy, which can be used in future research. Data on financial literacy used here was based on the results of the survey research that was conducted on a suitable sample of students at the University of Zagreb. The questionnaire consisted of five parts: financial knowledge, financial attitudes, financial behavior, practical knowledge and basic socio-

\footnotetext{
* Corresponding author. 
demographic questions ${ }^{* *}$. The first three parts were created following the OECD/INFE methodology for measuring financial literacy [16], while the fourth part makes an addition to the standardized questionnaire. The results of qualitative research have been used to produce a financial literacy measure through factor analysis. The measurement model consists of four manifest variables, each calculated based on correct answers in the corresponding part of the questionnaire, whose estimation in the end results in a composite indicator of financial literacy. Answers in categories Knowledge and Practical Knowledge were marked 1 if objectively correct and 0 otherwise, whereas in categories Attitudes and Behavior the authors marked respondent's behavior and attitudes as appropriate if it was in accordance with the concept of financial literacy, with $100 \%$ as the maximum respondents could achieve. The assessed measure of financial literacy of students at the University of Zagreb enables the comparison of students in different fields of study and with different socio-demographic characteristics, while also indicating where a potential for financial literacy programs exists.

The remainder of this paper is organized as follows. Following the Introduction, in the second section the existing empirical research is explained. The third section is devoted to research methodology, while the results of our empirical work are reported in the fourth section. Conclusion and proposals for future research are provided in the fifth section.

\section{Previous Research}

Financial literacy has become the subject of extensive research since the onset of the global financial crisis. While there are many empirical studies on financial literacy, only a few have offered a specific measure of financial literacy. Literature review focuses solely on studies that provided such a measure. The methods used to measure financial literacy vary quite substantially, considering that different researchers and organizations have defined financial literacy in many different ways [8].

[18], [4], [7] and [15] used a performance test to assess financial literacy and their measure was based on the percent of correct answers in the test. [10], [13], [11], [6] and [14] measured financial literacy on a 3-item test, either from savings, investment or debt domain [8]. [12] and [17] apply factor analysis on multiple-choice items, separately considering basic and sophisticated financial literacy.

[1] concluded that it is possible to apply the same set of questions in different countries, based on which simple measures of financial literacy are obtained. However, the question is whether it is, based on a small number of questions, such as only 3 that were used in the research of [8] or [14], even possible to infer someone is financially literate or illiterate. [9] points out the shortcomings in the previously assessed measures that relate to the lack of a definition of financial literacy and demarcation between financial knowledge and education, a small number of survey questions and lack of criteria for concluding whether respondents are financially literate.

Our research attempts to correct these shortcomings in the empirical literature. In the beginning, the definition on which financial literacy measure is based on has been explained. The created questionnaire includes 25 items that test financial knowledge and the ability to use knowledge and skills towards achieving financial well-being. A single weighted average of

\footnotetext{
${ }^{* *}$ Fullquestionnaire is available upon request.
} 
correct/incorrect responses as well as desirable/undesirable behavior and attitudes (based on factor analysis) constitutes the measure of financial literacy that ranges from 0-100\%, making it easy to interpret.

\section{Methodology}

Our empirical work included a survey research based on which the financial literacy of students was assessed. A comprehensive questionnaire was created on the basis of the widely accepted definition of financial literacy as a combination of financial knowledge, attitudes and behavior, while it has also been supplemented with a fourth category, practical knowledge. Measure of financial literacy is developed using factor analysis and with the help of AMOS 5.0, a version of the SPSS software. Depending on the purpose of research, this type of analysis can be employed to explore new topics, which is the goal of the exploratory factor analysis, and to test defined hypotheses for which one needs confirmatory factor analysis [5], as used in this paper. Confirmatory factor analysis includes testing the validity of a measurement model, i.e. using metric indicators (manifest variables) for assumed latent (hidden) variables. A weight matrix is then determined based on the measurement model and the obtained weights are used in formulating the indicator of financial literacy. The measurement model consists of four manifest variables: Knowledge, Attitudes, Behavior and Practical Knowledge, each calculated based on correct answers in the corresponding part of the questionnaire, and the latent variable is Financial Literacy. The model is presented in Figure 1.

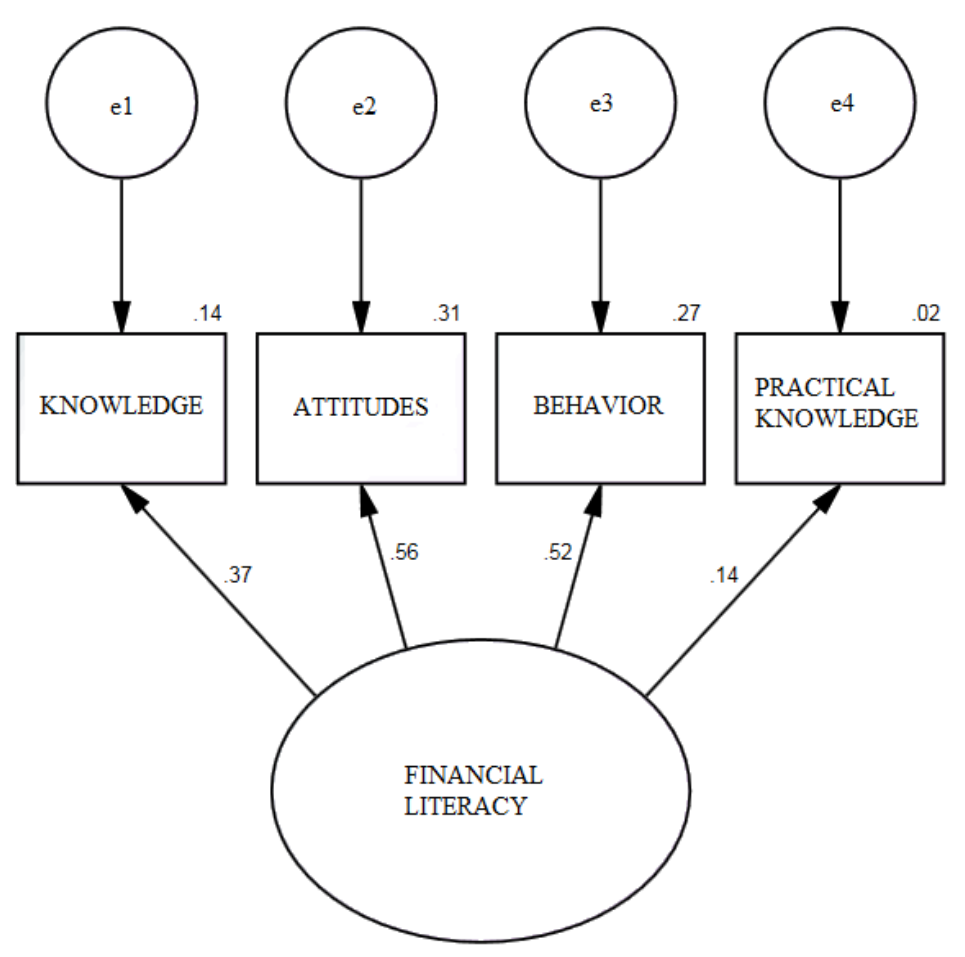

Figure 1: Measurement model for financial literacy

Parameters that link manifest and latent variables are called factor loadings. Factor loadings are standardized and show the intensity and direction of the connection of each manifest 
variable with a latent variable. All factor loadings are estimated by the maximum likelihood method and range from 0.139 to 0.556 , as can be seen in Table 1 .

\begin{tabular}{|c|c|c|}
\hline & & $\begin{array}{c}\text { Standardized } \\
\text { estimates }\end{array}$ \\
\hline Knowledge & $\leftarrow \quad \mathrm{F} 1$ & 0.371 \\
\hline Attitudes & $\leftarrow \quad \mathrm{F} 1$ & 0.556 \\
\hline Behavior & $\leftarrow \quad \mathrm{F} 1$ & 0.522 \\
\hline $\begin{array}{l}\text { Practical } \\
\text { knowledge }\end{array}$ & $\leftarrow \quad \mathrm{F} 1$ & 0.139 \\
\hline
\end{tabular}

Table 1: Standardized factor loadings

Squared values of multiple correlation coefficients are presented next to each manifest variable, showing the percentage of the variance explained. They range from $2 \%$ to $31 \%$, as visible in Table 2. The remaining part of the variance is unexplained and attributed to a random error component and unknown factors or residuals. Variables representing residuals are denoted by $e_{1}, e_{2}, e_{3}$ and $e_{4}$ in Figure 1 .

\begin{tabular}{|l|c|}
\hline & $\begin{array}{c}\text { Standardized } \\
\text { estimates }\end{array}$ \\
\hline Knowledge & 0.019 \\
Attitudes & 0.273 \\
Behavior & 0.309 \\
Practical & 0.137 \\
knowledge & \\
\hline
\end{tabular}

Table 2: Squared values of multiple correlation coefficients

The significance of factor loadings is tested based on their non-standardized values. Table 3 gives non-standardized values of the estimated parameters, their standard error, test size, and $p$-values.

\begin{tabular}{|lc|c|c|c|c|}
\hline & & Estimates & $\begin{array}{c}\text { Standard } \\
\text { error }\end{array}$ & Critical ratio & $p$-value \\
\hline Knowledge & $\leftarrow$ F1 & 0.371 & 0.151 & 4.490 & $* * *$ \\
Attitudes & $\leftarrow$ F1 & 0.556 & 0.165 & 8.169 & $* * *$ \\
Behavior & $\leftarrow$ F1 & 0.522 & 0.117 & 10.376 & $* * *$ \\
Practical & $\leftarrow$ F1 & 0.139 & 0.108 & 3.811 & $* * *$ \\
knowledge & & & & \\
\hline
\end{tabular}

Note: ${ }^{* * *}$ denotes significance at $1 \%$ level.

Table 3: Unstandardized values of the estimated parameters

Comparing the standardized coefficients, the value of 0.556 is the largest, which means that the component Attitudes contributes the most to the measurement of financial literacy, 
while the direction of its impact is positive and statistically significant. In addition, the percentage of variance explained by this variable is $31 \%$. Other estimated coefficients are provided in Table 2 and interpreted in a similar way [3].

Table 4 shows that 7 parameters are estimated in the model, and the chi-square value is 18.6197 with 3 degrees of freedom. The corresponding $p$-value is greater than $1 \%$, which confirms that the model is suitably specified, i.e. statistically significant. Thus, the negligible $\chi 2$ is the proof that the theory is correct, while a significant $\chi 2$ would indicate that the model cannot encompass the relationships explained by empirical data. Also, in comparison to the exploratory methods within multivariate analysis, which always calculate all the parameters and therefore operate with zero degrees of freedom $(\mathrm{df}=0)$, the confirmatory factor analysis allows for inferential testing of the model. However, the chi-square values alone cannot be taken as the sole indicator of appropriateness, but are usually divided by degrees of freedom. In this case, it is considered that the model is appropriate if the ratio of the chi-square value and degrees of freedom is between one and three. The value of 2.873 is satisfactory. This model fit index is more commonly used because of the risk that the model will be over-identified or seemingly good, while it is actually not [5].

\begin{tabular}{|c|c|c|c|c|c|}
\hline & $\begin{array}{c}\text { Number of } \\
\text { parameters }\end{array}$ & $\chi 2$ & $\begin{array}{c}\text { Degrees } \\
\text { of } \\
\text { freedom }\end{array}$ & $p$-value & $\chi 2 / \mathrm{df}$ \\
\hline Model & 7 & 8.6197 & 3 & 0.0337 & 2.873 \\
\hline
\end{tabular}

Table 4: Chi-square values

To examine the adequacy of the estimated model, four common model fit indices are used: Root Mean Square Residual (RMSR), Goodness of Fit Index (GFI), Comparative Fit Index (CFI) and Normed Fit Index (NFI) [5]. The results are presented in Table 5.

\begin{tabular}{|c|c|c|c|c|}
\hline & RMSR & GFI & CFI & NFI \\
\hline Model & 0.003 & 0.945 & 0.937 & 0.902 \\
\hline
\end{tabular}

Table 5: Model fit indices

The small value of the RMSR index indicates a good model fit, as do all the other indices, since their values are greater than 0.9 .

Results of the confirmatory factor analysis are further used for obtaining the corresponding weights of indicators of financial literacy. All of the indicators have been normalized using the min-max normalization since some were expressed as percentages, and some as integers. This enables comparison of indicators that were measured using different measuring scales. The normalization process results in values from 0 to 1 or from $0 \%$ to $100 \%$, which is ultimately easier to interpret. The formula for such a process of normalization is as follows:

$$
x^{\prime}=\frac{x_{i}-x_{\min }}{x_{\max }-x_{\min }} .
$$

In the first phase, components of financial literacy are assigned weights. The statistical software here chosen is Expert Choice. In the second phase, based on weights, a weighted 
average of the normalized values of the components is calculated, in order to obtain the indicator of financial literacy. The value of the indicator of Financial Literacy $(F L)$ will express the level or degree of financial literacy on a scale of $0 \%$ to $100 \%$.

To determine the weight of criteria the eigenvector method was used. According to [2], in the eigenvector method the decision-maker decides on the relative importance between the two indicators, or better said, compares all possible pairs of indicators $\left(f_{i}, f_{j}\right.$, for $\left.i \neq j\right)$ by their importance. Number of assessments required by the decision-maker is equal to the number of combinations without repetition of the second row of $p$ elements, or:

$$
\left(\begin{array}{l}
p \\
2
\end{array}\right)=\frac{p \cdot(p-1)}{2}
$$

where $p$ is the number of criteria of the second level of the model of aggregate indicator. This means that for the 4 indicators of $F L$ it is necessary to determine 6 weight ratios according to the formula:

$$
a_{i j}=\frac{w_{i}}{w_{j}}
$$

Based on the obtained results, weight ratios for all pairs of indicators are thereafter determined and a matrix of weight ratios $A$ is formed. Its elements are estimates of coefficients $a_{i j}$.

$$
A=\left[\begin{array}{cccc}
a_{11} & a_{12} & \ldots & a_{1 n} \\
a_{21} & a_{22} & \ldots & a_{2 n} \\
\ldots & \ldots & \ddots & \ldots \\
a_{n 1} & a_{n 2} & \ldots & a_{n n}
\end{array}\right]=\left[\begin{array}{cccc}
w_{1} / w_{1} & w_{1} / w_{2} & \ldots & w_{1} / w_{n} \\
w_{2} / w_{1} & w_{2} / w_{2} & \ldots & w_{2} / w_{n} \\
\ldots & \ldots & \ddots & \ldots \\
w_{n} / w_{1} & w_{n} / w_{2} & \ldots & w_{n} / w_{n}
\end{array}\right]
$$

The largest eigenvalue in matrix $A$ was found by the eigenvector method, which is used to solve this linear system of equations:

$$
\begin{gathered}
\left(A-\lambda_{\max } I\right) \cdot w=0 \\
\sum_{i=1}^{k} w_{i}=1
\end{gathered}
$$

where $I$ is the identity matrix, $w_{i}$ are weights of coefficients and $\lambda_{\max }$ the maximum eigenvalue.

By solving the above-mentioned system, the vector of weights of each individual indicator $w_{i}, i=1,2, \ldots, p$ is obtained. Although it is customary to use the Saaty scale to express the intensity of importance, weight ratios are expressed here as ratios of factor loadings obtained from the confirmatory factor analysis. The ratios of factor loadings are scientifically justified indicators of importance and are more objective than the subjective assessments of experts, used in most empirical studies. The advantage of using the factor loadings is that the above ratios need not be integers, so in this case the degree of inconsistency equals zero. The coefficients of matrix $A$ are presented in Table 6 .

Since matrix $A$ is reciprocal because $a_{j i}=\frac{1}{a_{i j}}$, only the elements above the main diagonal are shown in Table 6 . They serve for comparison of pairs of manifest variables. Matrix $A$ is consistent, which was anticipated considering that the weight ratios were estimated based on factor loadings, instead of subjective assessments, which usually leads to erroneous judgments. 


\begin{tabular}{|l|l|l|l|l|}
\hline & Knowledge & Attitudes & Behavior & $\begin{array}{l}\text { Practical } \\
\text { knowledge }\end{array}$ \\
\hline Knowledge & & 1.50 & 1.41 & $(2.67)$ \\
\hline Attitudes & & & $(1.07)$ & $(4.00)$ \\
\hline Behavior & & & & $(3.76)$ \\
\hline $\begin{array}{l}\text { Practical } \\
\text { knowledge }\end{array}$ & $\begin{array}{l}\text { Inconsistency: } \\
0.00\end{array}$ & & & \\
\hline
\end{tabular}

Table 6: Estimated Coefficients of Matrix $A$

The parentheses in Table 6 indicate that the observed indicator has a lower importance than the indicator to which it is compared. Therefore, observing the importance of the indicator Knowledge in relation to the other three indicators, it can be concluded that Knowledge is of greater importance than indicators Attitudes and Behavior, but less significant than Practical Knowledge. To be precise, Knowledge has importance 1.5 times greater than Attitudes, and is 1.41 times more important than Behavior, whilst Knowledge is less significant than Practical Knowledge by 2.67 times. The remaining pairs are interpreted in a similar way.

The concluding step was to calculate the corresponding weights of indicators by solving the linear system of equations in the above-mentioned expression and, with the help of the program Expert Choice, the composite indicator of financial literacy was obtained as expressed by the formula:

$$
\begin{gathered}
F P_{i}=0.198 \cdot \text { KNOWLEDGE }+0.132 \cdot \text { ATTITUDES }+0.141 \cdot \text { BEHAVIOR } \\
+0.529 \cdot P R A C T I C A L \text { KNOWLEDGE }
\end{gathered}
$$

Presented weights indicate the relative importance of each component of financial literacy. Practical Knowledge has the highest relative importance (52.9\%); it is followed by Knowledge with $19.8 \%$, and then Behavior with $14.1 \%$, whereas the least important indicator is Attitudes with $13.2 \%$. These coefficients reflect the characteristics of the analyzed sample, meaning that in a study of a disparate population, they could be completely different, but their primary purpose was to identify relative importance of the components of financial literacy used in this case.

\section{Results and Discussion}

The assessed measure of financial literacy of students at the University of Zagreb enabled the comparison of students in different fields of study and with different sociodemographic characteristics. Students were compared with respect to their study's characteristics, gender, year of study, grade point average and work experience. Table 7 summarizes the results of Satterthwaite-Welch $t$-tests (for dichotomous questions) and Welch ANOVA (for multiple-choice questions) which are used when unequal variances are assumed.

Table 7 compares the level of financial literacy of students according to the characteristics of their studies and their socio-demographic features in order to detect the determinants of financial literacy. The results indicate great difference in financial literacy between students who took a financial course and those who have not. The null hypothesis is rejected at the significance level of $1 \%$, which confirms the importance of financial courses within formal education. This is closely related to the second criterion that assumes the level of 
financial literacy depends on their study field. The results prove a great heterogeneity in financial literacy among students in six different fields of study.

\begin{tabular}{|l|l|c|c|c|}
\hline \multicolumn{1}{|c|}{ Criteria } & \multicolumn{1}{|c|}{ Test } & $\begin{array}{c}\text { Degrees of } \\
\text { freedom }\end{array}$ & Test statistic & Probability \\
\hline (1) Financial courses & $\begin{array}{l}\text { Satterthwaite-Welch } \\
t \text {-test }\end{array}$ & 1241.687 & $6.966494^{* * *}$ & 0.0000 \\
\hline (2) Scientific field & Welch ANOVA & $(5,224.492)$ & $10.93281^{* * *}$ & 0.0000 \\
\hline (3) Year of study & Welch ANOVA & $(5,345.911)$ & $10,04932^{* * *}$ & 0,0000 \\
\hline (4) Grade point average & Welch ANOVA & $(5,334.340)$ & 1,255620 & 0,2829 \\
\hline (5) Gender & $\begin{array}{l}\text { Satterthwaite-Welch } \\
t \text {-test }\end{array}$ & 1106.511 & -1.427621 & 0.1537 \\
\hline (6) Work experience & $\begin{array}{l}\text { Satterthwaite-Welch } \\
t \text {-test }\end{array}$ & 371.2280 & $2.405151^{* *}$ & 0.0167 \\
\hline
\end{tabular}

Note: ${ }^{* * *}$ and ${ }^{* *}$ denote significance at $1 \%$ and $5 \%$ level respectively.

Table 7: Determinants of financial literacy

Students were then compared with respect to the year of study they were in and their grade point average. It was expected that students in a higher year of study will prove more financially literate. Since the means for different years of study differ significantly, it makes an important determinant of financial literacy. At most faculties, with the year of study, the grade point average increases, as most students find the first year to be the most difficult. It is assumed that students with a higher grade point average will be more financially literate, which is explained by greater interest, effort and willingness to acquire knowledge. However, the results of the corresponding Welch ANOVA show that this is not a significant determinant of financial literacy.

Within the research two socio-demographic characteristics were also tested as potential determinants. Based on the results of the $t$-test, the null hypothesis cannot be rejected in the case of gender, meaning that male and female students at the University of Zagreb demonstrated the same level of financial literacy. Lastly, $t$-test was performed to test whether students with work experience possess a higher level of financial literacy. Empirical data reached significance under the level of $5 \%$, which means that this hypothesis is supported. Further testing has shown that work experience is significant for all the other components of financial literacy and financial literacy as a whole.

The measure developed in this research demonstrated it is necessary to devote more attention to financial and economic issues within formal education. Taking financial courses largely contributed to students' financial literacy, together with a scientific field of study that also makes an important factor. As can be seen in the Appendix, students of the Faculty of Economics and Business are considerably more financially literate than their colleagues in other Faculties. After examining the structure of courses at the University, it can be concluded that an exceptionally large number of students complete their formal education without ever having encountered fundamental economic concepts, which they will certainly need in their adult life. That is why it is imperative to find ways to cover financial topics in non-economic studies. 


\section{Conclusion}

Financial literacy is a combination of knowledge, skills, attitudes and behavior that are indispensable in making sound financial decisions and achieving individual financial well-being [16]. Many higher education institutions have recognized the importance of this subject, while the number of projects and initiatives for financial literacy of students is growing exponentially. However, despite the great interest, so far, no systematic studies of financial literacy of students at any of the Croatian universities have been carried out, and this research aimed to rectify this. The main objective of this paper was to present a method of measuring students' financial literacy that can be used in modeling financial education policies. Data was obtained from a survey research conducted on a sample of students at the University of Zagreb. Using the confirmatory factor analysis and eigenvector method, a measure of financial literacy of students at the University of Zagreb was defined. It enabled the comparison of students in different fields of study and with different socio-demographic characteristics, while also indicating where the potential for financial literacy programs exists. Students were compared according to their study's characteristics, gender, year of study, grade point average and work experience to find the potential determinants of financial literacy.

Students who have taken some financial courses proved to be more financially literate, with a scientific field of study also being an important determinant of the level of financial literacy. Turning to other students' characteristics, tests showed that the year of study and work experience are statistically significant in this research, but grade point average and gender are not, as some previous studies concluded. The insights gained during this research are exceptionally important for the academic community and lay the groundwork for future studies of financial literacy. The research has indicated the importance of some sociodemographic factors and study program characteristics, which should be taken into account when creating the framework for action to improve the financial literacy of the student population.

\section{References}

[1] Atkinson, A., and Messy, F.-A. (2012). Promoting Financial Inclusion through Financial Education: OECD/INFE Evidence, Policies and Practice. OECD Working Papers on Finance, Insurance and Private Pensions, No. 34, Paris.

[2] Babić, Z. (2011). Modeli i metode poslovnog odlučivanja. Split: Faculty of Economics.

[3] Byrne, B. M. (2010). Structural Equation Modeling with AMOS: Basic Concepts, Applications and Programming. 2nd Ed. New York: Taylor \& Francis Group, LLC.

[4] Chen, H. and Volpe, R. P. (1998). An Analysis of Personal Financial Literacy Among College Students. Financial Services Review, 7(2), 107-128.

[5] Hair, J. F., Black, W. C., Babin, B. J., and Anderson, R. E. (2010) Multivariate Data Analysis: A Global Perspective. 7th Ed. New Jersey: Pearson Education, Inc.

[6] Hastings, J. S., and Tejeda-Ashton, L. (2008). Financial literacy, information, and demand elasticity: Survey and experimental evidence from Mexico. NBER Working Paper 14538.

[7] Hilgert, M., Hogarth, J., and Beverley, S. (2003). Household financial management: The connection between knowledge and behavior. Federal Reserve Bulletin, 89(7), 309-322. 
[8] Hung, A. A., Parker, A. M., and Yoong, J. K. (2009). Defining and Measuring Financial Literacy. RAND Labor and Population. Working Paper No. WR-708, Santa Monica.

[9] Huston, S. J. (2010). Measuring Financial Literacy. The Journal of Consumer Affairs, 44(2), 296-316.

[10] Lusardi, A., and Mitchell, O. S. (2006). Financial Literacy and Planning: Implications for Retirement Well-Being. Pension Research Council Working Paper No. 2006-01.

[11] Lusardi, A., and Mitchell, O. S. (2007a). Baby Boomer Retirement Security: The Roles of Planning, Financial Literacy, and Housing Wealth. Journal of Monetary Economics, 54(1), 205-224.

[12] Lusardi, A., and Mitchell, O. S. (2007b). Financial Literacy and Retirement Planning: New Evidence from the Rand American Life Panel. MRRC Working Paper No. 2007157, 1-33.

[13] Lusardi, A., and Mitchell, O. S. (2008). Planning and Financial Literacy: How Do Women Fare?. CeRP Working Paper No. 72, 1-10.

[14] Lusardi, A., and Tufano, P. (2009). Debt Literacy, Financial Experiences and Overindebtedness. NBER Working Paper No. 14808, 1-46.

[15] Mandell, L. (2004). Financial Literacy: Are We Improving? Results of the 2004 National Jump\$tart Survey. http://www.jumpstart.org/assets/files/2008SurveyBook.pdf [Accessed 03/06/17]

[16] OECD International Network on Financial Education (OECD/INFE). (2016). International Survey of Adult Financial Literacy Competencies.

http://www.oecd.org/daf/fin/financial-education/OECD-INFE-International-Survey-ofAdult-FInancial-Literacy-Competencies.pdf [Accessed 03/06/17]

[17] Van Rooij, M., Lusardi, A., and Alessie, R. (2007). Financial Literacy and Stock Market Participation. NBER Working Paper No. 13565, 1-46.

[18] Volpe, R. P., Chen, H., and Pavlicko, J. J. (1996). Personal investment literacy among college students: A survey. Financial Practice and Education, 6(2), 86-94. 


\section{Appendix}

\begin{tabular}{|c|c|c|c|c|c|}
\hline \multicolumn{2}{|c|}{ Constituent Units } & Measure & Std. Dev. & Min & Max \\
\hline \multicolumn{2}{|c|}{ Biomedicine and health sciences } & 0.5681 & 0.0956 & 0.3003 & 0.8568 \\
\hline 1 & Faculty of Pharmacy and Biochemistry & 0.6202 & 0.0937 & 0.4505 & 0.8568 \\
\hline 2 & School of Medicine & 0.5394 & 0.0864 & 0.3003 & 0.7916 \\
\hline 3 & School of Dental Medicine & 0.6197 & 0.1019 & 0.4151 & 0.7450 \\
\hline 4 & Faculty of Veterinary Medicine & 0.5431 & 0.0742 & 0.4346 & 0.6865 \\
\hline \multicolumn{2}{|c|}{ Biotechnical sciences } & 0.5480 & 0.1246 & 0.2431 & 0.8597 \\
\hline 5 & Faculty of Agriculture & 0.5465 & 0.1165 & 0.2973 & 0.7951 \\
\hline 6 & Faculty of Food Technology and Biotechnology & 0.5859 & 0.1383 & 0.3295 & 0.8597 \\
\hline 7 & Faculty of Forestry & 0.5202 & 0.1247 & 0.2431 & 0.7666 \\
\hline \multicolumn{2}{|c|}{ Social sciences and humanities } & 0.6092 & 0.1266 & 0.0675 & 0.9357 \\
\hline 8 & Faculty of Education and Rehabilitation Sciences & 0.5872 & 0.1073 & 0.3276 & 0.7698 \\
\hline 9 & Faculty of Economics and Business & 0.7016 & 0.1074 & 0.4348 & 0.9357 \\
\hline 10 & Faculty of Organization and Informatics & 0.6173 & 0.1242 & 0.3613 & 0.8528 \\
\hline 11 & Faculty of Political Science & 0.5984 & 0.1252 & 0.2860 & 0.8862 \\
\hline 12 & Faculty of Humanities and Social Sciences & 0.5929 & 0.1256 & 0.2691 & 0.9208 \\
\hline 13 & Catholic Faculty of Theology & 0.5397 & 0.1373 & 0.1943 & 0.7289 \\
\hline 14 & Faculty of Kinesiology & 0.5272 & 0.1401 & 0.0675 & 0.7268 \\
\hline 15 & Faculty of Law & 0.5957 & 0.1076 & 0.2900 & 0.8288 \\
\hline 16 & University Centre for Croatian s & 0.5914 & 0.0949 & 0.3886 & 0.8281 \\
\hline 17 & Faculty of Teacher Education & 0.5444 & 0.1170 & 0.2217 & 0.8320 \\
\hline \multicolumn{2}{|c|}{ Natural sciences } & 0.6167 & 0.0959 & 0.3336 & 0.8124 \\
\hline 18 & Faculty of Science & 0.6167 & 0.0959 & 0.3336 & 0.8124 \\
\hline \multicolumn{2}{|c|}{ Technical sciences } & 0.5897 & 0.1153 & 0.1183 & 0.8979 \\
\hline 19 & Faculty of Architecture & 0.6053 & 0.1242 & 0.2977 & 0.8979 \\
\hline 20 & Faculty of Electrical Engineering and Computing & 0.5972 & 0.1102 & 0.1183 & 0.8583 \\
\hline 21 & Faculty of Chemical Engineering and Technology & 0.6058 & 0.1144 & 0.3373 & 0.8673 \\
\hline 22 & Faculty of Transport and Traffic Sciences & 0.5725 & 0.1162 & 0.2583 & 0.8158 \\
\hline 23 & $\begin{array}{l}\text { Faculty of Mechanical Engineering and Naval } \\
\text { Architecture }\end{array}$ & 0.5961 & 0.1093 & 0.2790 & 0.8102 \\
\hline 24 & Faculty of Geodesy & 0.6147 & 0.1283 & 0.3484 & 0.8340 \\
\hline 25 & Faculty of Geotechnical Engineering & 0.6088 & 0.1574 & 0.3939 & 0.8132 \\
\hline 26 & Faculty of Civil Engineering & 0.5965 & 0.0934 & 0.4296 & 0.7666 \\
\hline 27 & Faculty of Graphic Arts & 0.6268 & 0.0995 & 0.4341 & 0.8343 \\
\hline 28 & Faculty of Metallurgy & 0.5002 & 0.1523 & 0.3688 & 0.6672 \\
\hline 29 & $\begin{array}{l}\text { Faculty of Mining. Geology and Petroleum } \\
\text { Engineering }\end{array}$ & 0.5390 & 0.1026 & 0.3484 & 0.7556 \\
\hline 30 & Faculty of Textile Technology & 0.5610 & 0.1391 & 0.3060 & 0.8536 \\
\hline \multicolumn{2}{|c|}{ Artistic fields } & 0.5092 & 0.1483 & 0.1464 & 0.7755 \\
\hline 31 & Academy of Dramatic Arts & 0.5578 & 0.1145 & 0.4304 & 0.7755 \\
\hline 32 & Academy of Fine Arts & 0.4081 & 0.1569 & 0.1464 & 0.6067 \\
\hline 33 & Academy of Music & 0.5574 & 0.1257 & 0.3296 & 0.7576 \\
\hline \multicolumn{2}{|c|}{ TOTAL: } & 0.5947 & 0.1220 & 0.0675 & 0.9357 \\
\hline
\end{tabular}

